http://jmscr.igmpublication.org/home/ ISSN (e)-2347-176x ISSN (p) 2455-0450

crossref DOI: https://dx.doi.org/10.18535/jmscr/v8i9.22

\title{
Clinical characteristics of pregnant women who undergo elective cesarean section under subarachnoid block
}

\author{
Authors \\ Pooja Bhari $^{*}$, Sharmin Ara Begum ${ }^{2}$, Dilip Kumar Bhowmick ${ }^{3}$, Begum Maksuda \\ Farida Akhtar ${ }^{4}$, Mohammad Anisur Rahman ${ }^{5}$, MA Hye ${ }^{6}$, Akhtaruzzaman AKM ${ }^{7}$ \\ ${ }^{1}$ MD Phase B Anaesthesia Resident, Department of Anaesthesia, Analgesia and Intensive Care Medicine, \\ Bangabandhu Sheikh Mujib Medical University, Dhaka, Bangladesh \\ ${ }^{2}$ Junior Consultant, Department of Anaesthesia, Analgesia and Intensive Care Medicine, National Institute of \\ Traumatology and Orthopaedic Rehabilitation, Sheer E Bangla Nagar, Dhaka, Bangladesh \\ ${ }^{3}$ Associate Professor, Department of Anaesthesia, Analgesia and Intensive Care Medicine, Bangabandhu Sheikh \\ Mujib Medical University, Dhaka, Bangladesh \\ ${ }^{4}$ Associate Professor, Department of Obstetrics and Gynaecology, Institute Child and maternal Health, Matuail, \\ Dhaka, Bangladesh \\ ${ }^{5}$ Assistant Professor, Department of Anaesthesiology, Kuwait Bangladesh Friendship Hospital, Dhaka, Bangladesh \\ ${ }^{6}$ Professor, Department of Anaesthesia, Analgesia and Intensive Care Medicine, Bangabandhu Sheikh Mujib Medical \\ University, Dhaka, Bangladesh \\ ${ }^{7}$ Professor and Chairman, Department of Anaesthesia, Analgesia and Intensive Care Medicine, Bangabandhu Sheikh \\ Mujib Medical University, Dhaka, Bangladesh \\ *Corresponding Author \\ Pooja Bhari
}

\begin{abstract}
Objective: In this study our main goal is to evaluate the clinical characteristics of pregnant women who undergo elective cesarean section under subarachnoid block.

Method: This randomized Controlled trial (RCT) study was carried out at Obstetric Operation Theatre under supervision of Department of Anaesthesia, Analgesia and Intensive Care Medicine, BSMMU from 12 months. A total of 90 parturient admitted for elective caesarean section in Obstetrics and Gynaecology Department of BSMMU were included in the study divided into two groups. Where Group P was the phenylephrine group and Group E was the ephedrine group. Each group had sample size of 45.

Results: During the study, in group $P, 64.4 \%$ belong to 21-30 years age group, 26.7\% belong to $31-39$ years age group and only $8.9 \%$ belong to $\leq 20 y e a r s$ age group. Whereas in group E quite similar results were found where $73.3 \%$ belong to $21-30$ years age group, $22.2 \%$ belong to 31 -39 years age group and only $4.4 \%$ belong to $\leq 20 y e a r s$ age group. Mean heart rate was higher in group E than group P. Heart rate was very highly statistically significant at 3 minutes, 6 minutes, 9 minutes, 12minutes before delivery, 5 minutes, 10 minutes, 15 minutes, 20 minutes, 25 minutes, 30 minutes, 35 minutes after delivery. Mean systolic blood pressure was significantly higher in group $P$ than group E. systolic blood pressure was statistically significant at baseline, 3 minutes, 6 minutes, 9 minutes, 12 minutes before delivery and at 20 minutes, 25 minutes, 30 minutes, 35 minutes, 40 minutes, 45 minutes after delivery. But it was statistically not significant at 15 minutes before delivery and 5 minutes, 10 minutes, 15 minutes and 50 minutes after delivery.

Conclusion: Subarachnoid (spinal) block is a safe and effective alternative to general anesthesia involving the lower extremities and surgeries below the umbilicus. Further studies are needed for better outcome.

Keywords: Elective cesarean section, Subarachnoid block (SAB), anaesthetic technique.
\end{abstract}




\section{Introduction}

Subarachnoid block (SAB) is generally the most preferred and commonly practiced anaesthetic technique for caesarean section (CS) that requires highest degree of care because the anaesthesiologist has to look after two individuals, the mother and the fetus. It has many advantages of being easy administration technique, rapid onset of action, relatively less adverse effects, cost-effectiveness and the most important thing that patient remains aroused throughout the procedure. ${ }^{1}$ It has also been shown to block the stress response to surgery, decrease intra operative blood loss, and lower the incidence of postoperative thromboembolism and decreases morbidity and mortality in high risk patients. ${ }^{2}$ There is an opportunity for the mother to be awake during delivery to experience and participate in the birthing process as well as to interact and bond with the baby. It is induced by injecting local anesthetic into the cerebrospinal fluid in the subarachnoid space at either L2-3, L34, L4-5 intervertebral space.

Like any other medical procedure, there are risks associated with subarachnoid block. These can occur even though when patient is monitored carefully and anaesthesiologist takes special precaution to avoid them. It is estimated that around $80 \%$ of patients undergoing caesarean section under subarachnoid block develop hypotension during the procedure without prophylactic management. ${ }^{3}$ In this study our main goal is to evaluate the clinical characteristics of pregnant women who undergo elective cesarean section under subarachnoid block.

\section{Objective}

\section{General Objective}

- To evaluate the clinical characteristics of pregnant women who undergo elective cesarean section under subarachnoid block.

\section{Specific Objective}

- To detect heart rate at different time intervals of the patients.
- To evaluate demographic status of the patients.

\section{Methodology \\ Study Type \\ This study was a randomized Controlled trial (RCT) study.}

\section{Place and period of study}

The study was carried out at Obstetric Operation Theatre under supervision of Department of Anaesthesia, Analgesia and Intensive Care Medicine, BSMMU from 12 months.

\section{Sample Size}

A total of 90 parturients admitted for elective caesarean section in Obstetrics and Gynaecology Department of BSMMU according to the inclusion and exclusion criteria. Patients were randomly divided into two groups using consecutive closed envelopes with random numbers processed by a health care provider who was not involved with the study in any respect. Where Group P was the phenylephrine group and Group E was the ephedrine group. Each group had sample size of 45 .

\section{Data Collection Procedure}

This study was conducted at Obstetric Operation Theatre of Bangabandhu Sheikh Mujib Medical University (BSMMU). After receiving of approval from the Institutional Review Board (IRB), BSMMU and informed written consent from each individual 90 patients were enrolled in this study undergoing elective caesarean section who had fulfilled the inclusion and exclusion criteria. Preoperative evaluation was done with thorough history, physical examination and relevant laboratory investigations. All patients were randomly divided into two groups using consecutive closed envelopes with random numbers processed by a health care provider who was not involved with the study in any respect Where Group P ( $\mathrm{n}=45): 100 \mu \mathrm{g}$ phenylephrine and in Group $\mathrm{E}(\mathrm{n}=45)$ : $10 \mathrm{mg}$ Ephedrine was 
induced. Demographic and clinical data including age, weight, height, body mass index (BMI) and American Society of Anaesthesiologist (ASA) physical status scores were recorded for all patients. All patients had the standard monitoring including continuous electrocardiography (ECG) (lead II), heart rate (HR), non-invasive blood pressure (NIBP) measured and oxygen saturation via continuous pulse oximetry ( $\mathrm{SpO} 2)$. Intravenous (IV) access with $18 \mathrm{G}$ IV cannula was established preferably on the non-dominant hand vein. Injection Ranitidine $50 \mathrm{mg}$ and Metoclopramide $10 \mathrm{mg}$ was given intravenously half an hour before operation.

\section{Data analysis}

The statistical analysis was carried out using the Statistical Package for Social Sciences version 23.0 for Windows. Qualitative variables of this study have been expressed as percentage. Quantitative variables are expressed as mean \pm standard deviation. Comparison was calculated by Chi-square test for the categorical variables \& unpaired t-test for the continuous variables. $\mathrm{P}$ values $<0.05$ were considered as statistically significant.

\section{Results}

In table-1 shows distributions of the patients according age group where in group $\mathrm{P}, 64.4 \%$ belong to $21-30$ years age group, $26.7 \%$ belong to 31-39 years age group and only $8.9 \%$ belong to $\leq 20$ years age group. Whereas in group $\mathrm{E}$ quite similar results were found where $73.3 \%$ belong to 21-30 years age group, $22.2 \%$ belong to $31-39$ years age group and only $4.4 \%$ belong to $\leq 20$ years age group. The following table is given below in detail:

Table-1: Distributions of the patients according age group

\begin{tabular}{lccc}
\hline variables & $\begin{array}{c}\text { Group P } \\
(\mathbf{n = 4 5}) \\
\mathbf{n}(\boldsymbol{\%})\end{array}$ & $\begin{array}{c}\text { Group E } \\
(\mathbf{n = 4 5}) \\
\mathbf{n}(\boldsymbol{\%})\end{array}$ & p-value \\
\hline Age (years) & & & \\
$\leq 20$ & $4(8.9)$ & $2(4.4)$ & 0.575 \\
$21-30$ & $29(64.4)$ & $33(73.3)$ & \\
$31-39$ & $12(26.7)$ & $10(22.2)$ & 0.802 \\
Mean \pm SD & $28.16 \pm 4.62$ & $27.91 \pm 4.59$ & \\
\hline
\end{tabular}

In table-2 shows demographic characteristics of the patients where in group $\mathrm{P}$ mean $\mathrm{BMI}$ was
$24.98 \pm 2.53$ and in group $\mathrm{E}$ it was $24.88 \pm 2.48$. The following table is given below in detail:

Table-2: Demographic characteristics of the patients

\begin{tabular}{lccc}
\hline variables & $\begin{array}{c}\text { Group P } \\
(\mathbf{n}=\mathbf{4 5}) \\
\text { Mean } \pm \text { SD }\end{array}$ & $\begin{array}{c}\text { Group E } \\
(\mathbf{n}=\mathbf{4 5}) \\
\text { Mean } \pm \text { SD }\end{array}$ & p-value \\
\hline Weight & $65.93 \pm 5.87$ & $66.18 \pm 6.00$ & 0.846 \\
Height & $1.62 \pm 0.04$ & $1.63 \pm 0.04$ & 0.538 \\
BMI & $24.98 \pm 2.53$ & $24.88 \pm 2.48$ & 0.859 \\
\hline
\end{tabular}

Table-3 shows the comparison of parturient according to gestational age between the two groups. The highest number of parturient in both the group were at $37+$ weeks of gestation. The following table is given below in detail: 
Table 3: Distribution of the parturient according to gestational age

\begin{tabular}{lccc}
\hline $\begin{array}{l}\text { Gestational age } \\
\text { (weeks) }\end{array}$ & $\begin{array}{c}\text { Group P } \\
(\mathbf{n = 4 5 )}\end{array}$ & $\begin{array}{c}\text { Group E } \\
(\mathbf{n = 4 5 )}\end{array}$ & p-value \\
\hline $36+$ & $1(2.2)$ & $6(13.3)$ & $0.025^{*}$ \\
37 & $3(6.7)$ & $0(0.0)$ & \\
$37+$ & $19(42.2)$ & $11(24.4)$ & \\
38 & $5(11.1)$ & $9(20.0)$ & \\
$38+$ & $7(15.6)$ & $8(17.8)$ & \\
39 & $4(8.9)$ & $2(4.4)$ & \\
$39+$ & $6(13.3)$ & $4(8.9)$ & \\
40 & $0(0.0)$ & $5(11.1)$ & \\
\hline
\end{tabular}

$\mathrm{P}$ value $<0.05$ is considered as significant. Chi-square test was done to measure the level of significance *-significant

Table-4 shows heart Rate at different time intervals between two groups. Mean heart rate was higher in group $\mathrm{E}$ than group $\mathrm{P}$. Heart rate was very highly statistically significant at 3 minutes, 6 minutes, 9 minutes, 12 minutes before delivery, 5 minutes, 10 minutes, 15 minutes, 20 minutes, 25 minutes, 30 minutes, 35 minutes after delivery. However, it was statistically not significant at the baseline, 40 minutes, 45 minutes, 50 minutes after delivery. The following table is given below in detail:

Table-4: Heart Rate at different time intervals between two groups

\begin{tabular}{|c|c|c|c|}
\hline Heart rate (bpm) & $\begin{array}{c}\text { Group P } \\
(n=45)\end{array}$ & $\begin{array}{c}\text { Group E } \\
(n=45)\end{array}$ & p-value \\
\hline Baseline & $81.73 \pm 5.36$ & $83.22 \pm 3.35$ & $0.118^{\mathrm{ns}}$ \\
\hline \multicolumn{4}{|l|}{ Before delivery } \\
\hline At 3 minutes & $84.02 \pm 5.20$ & $87.20 \pm 2.94$ & $0.001^{* *}$ \\
\hline At 6 minutes & $83.93 \pm 4.68$ & $87.82 \pm 3.52$ & $<0.001^{* * *}$ \\
\hline At 9 minutes & $82.51 \pm 5.50$ & $87.09 \pm 4.35$ & $<0.001^{* * *}$ \\
\hline At 12 minutes & $80.87 \pm 5.27$ & $84.53 \pm 3.59$ & $<0.001^{* * *}$ \\
\hline At 15 minutes & $77.61 \pm 4.91$ & $84.83 \pm 3.74$ & $<0.001^{* * *}$ \\
\hline \multicolumn{4}{|l|}{ After delivery } \\
\hline At 5 minutes & $88.69 \pm 5.21$ & $96.44 \pm 3.68$ & $<0.001^{* * *}$ \\
\hline At 10 minutes & $88.62 \pm 4.24$ & $96.89 \pm 4.49$ & $<0.001^{* * *}$ \\
\hline At 15 minutes & $86.53 \pm 5.14$ & $92.07 \pm 5.03$ & $<0.001^{* * *}$ \\
\hline At 20 minutes & $83.87 \pm 5.25$ & $89.42 \pm 5.49$ & $<0.001^{* * *}$ \\
\hline At 25 minutes & $83.60 \pm 5.57$ & $87.36 \pm 3.75$ & $<0.001^{* * *}$ \\
\hline At 30 minutes & $81.58 \pm 5.96$ & $86.00 \pm 3.69$ & $<0.001^{* * *}$ \\
\hline At 35 minutes & $81.67 \pm 5.54$ & $83.98 \pm 4.78$ & $0.037^{*}$ \\
\hline At 40 minutes & $82.18 \pm 6.02$ & $83.49 \pm 4.36$ & $0.240^{\mathrm{ns}}$ \\
\hline At 45 minutes & $82.21 \pm 6.32$ & $83.15 \pm 3.31$ & $0.407^{\mathrm{ns}}$ \\
\hline At 50 minutes & $79.00 \pm 4.96$ & $82.89 \pm 4.17$ & $0.078^{\mathrm{ns}}$ \\
\hline
\end{tabular}

Values are expressed as mean \pm SD. P value $<0.05$ is considered as significant. Unpaired t test was done to measure the level of significance

**- highly significant, *** - very highly significant, ns- non significant

In table-5 shows systolic Blood pressure. Mean systolic blood pressure was significantly higher in group $\mathrm{P}$ than group $\mathrm{E}$. systolic blood pressure was statistically significant at baseline, 3 minutes, 6 minutes, 9 minutes, 12 minutes before delivery and at 20 minutes, 25 minutes, 30 minutes, 35 minutes, 40 minutes, 45 minutes after delivery. But it was statistically not significant at 15 minutes before delivery and 5 minutes, 10 minutes, 15 minutes and 50 minutes after delivery. The following table is given below in detail: 
Table 5: Systolic Blood pressure at different time intervals between two groups

\begin{tabular}{lccc}
\hline $\begin{array}{l}\text { Systolic blood } \\
\text { pressure }(\mathbf{m m H g})\end{array}$ & $\begin{array}{c}\text { Group P } \\
(\mathbf{n = 4 5})\end{array}$ & $\begin{array}{c}\text { Group E } \\
(\mathbf{n = 4 5})\end{array}$ & p-value \\
\hline Baseline & $119.29 \pm 5.13$ & $116.84 \pm 5.33$ & $0.029^{*}$ \\
Before delivery & & & \\
At 3 minutes & $126.07 \pm 5.82$ & $114.22 \pm 5.74$ & $<0.001^{* * * *}$ \\
At 6 minutes & $125.76 \pm 5.35$ & $113.36 \pm 7.12$ & $<0.001^{* * *}$ \\
At 9 minutes & $122.04 \pm 4.98$ & $111.22 \pm 8.72$ & $<0.001^{* * *}$ \\
At 12 minutes & $117.60 \pm 6.38$ & $110.71 \pm 7.24$ & $<0.001^{* * *}$ \\
At 15 minutes & $113.11 \pm 8.74$ & $111.42 \pm 5.07$ & $0.550^{\text {ns }}$ \\
After delivery & & & \\
At 5 minutes & $111.62 \pm 7.98$ & $110.69 \pm 5.43$ & $0.518^{\text {ns }}$ \\
At 10 minutes & $110.58 \pm 8.52$ & $111.00 \pm 4.23$ & $0.767^{\text {ns }}$ \\
At 15 minutes & $110.42 \pm 8.28$ & $109.13 \pm 4.85$ & $0.370^{\text {ns }}$ \\
At 20 minutes & $111.71 \pm 5.93$ & $108.98 \pm 5.81$ & $0.030^{*}$ \\
At 25 minutes & $112.93 \pm 6.10$ & $108.98 \pm 6.06$ & $0.003^{* *}$ \\
At 30 minutes & $112.84 \pm 5.71$ & $108.80 \pm 5.01$ & $0.001^{* *}$ \\
At 35 minutes & $115.27 \pm 7.43$ & $110.29 \pm 4.70$ & $<0.001^{* * *}$ \\
At 40 minutes & $113.91 \pm 6.50$ & $110.42 \pm 5.48$ & $0.007^{* *}$ \\
At 45 minutes & $115.71 \pm 7.45$ & $11.15 \pm 6.23$ & $0.004^{* *}$ \\
At 50 minutes & $111.73 \pm 5.52$ & $109.78 \pm 6.14$ & $0.464^{\text {ns }}$ \\
\hline
\end{tabular}

Values are expressed as mean \pm SD. P value $<0.05$ is considered as significant. Unpaired $t$ test was done to measure the level of significance

*- significant, $* *$ - highly significant, $\quad * * *$ - very highly significant, ns- non significant

Table-6 shows diastolic Blood pressure at different time intervals of the patients. Diastolic blood pressure was statistically significant at 3 minutes, 6 minutes, 9 minutes, 12 minutes before delivery. But it was statistically not significant at baseline, 15 minutes before delivery and 5 minutes, 10 minutes, 15 minutes, 20 minutes, 25 minutes, 30 minutes, 35 minutes, 40 minutes and 50 minutes after delivery. The following table is given below in detail:

Table 6: Diastolic Blood pressure at different time intervals between two groups

\begin{tabular}{|c|c|c|c|}
\hline $\begin{array}{l}\text { Diastolic blood } \\
\text { pressure (mmHg) }\end{array}$ & $\begin{array}{l}\text { Group P } \\
(n=45)\end{array}$ & $\underset{(n=45)}{\operatorname{Group} E}$ & p-value \\
\hline Baseline & $66.22 \pm 5.16$ & $66.73 \pm 6.40$ & $0.678^{\mathrm{ns}}$ \\
\hline \multicolumn{4}{|l|}{ Before delivery } \\
\hline At 3 minutes & $73.33 \pm 7.79$ & $63.71 \pm 5.64$ & $<0.001^{* * *}$ \\
\hline At 6 minutes & $73.20 \pm 7.30$ & $63.02 \pm 6.28$ & $<0.001^{* * * *}$ \\
\hline At 9 minutes & $70.27 \pm 6.52$ & $62.02 \pm 6.94$ & $<0.001^{* * *}$ \\
\hline At 12 minutes & $66.22 \pm 6.81$ & $61.07 \pm 4.63$ & $<0.001^{* * *}$ \\
\hline At 15 minutes & $64.00 \pm 5.70$ & $61.92 \pm 4.52$ & $0.298^{\mathrm{ns}}$ \\
\hline \multicolumn{4}{|l|}{ After delivery } \\
\hline At 5 minutes & $59.53 \pm 6.01$ & $61.16 \pm 4.37$ & $0.147^{\mathrm{ns}}$ \\
\hline At 10 minutes & $59.20 \pm 5.74$ & $60.82 \pm 4.60$ & $0.143^{\mathrm{ns}}$ \\
\hline At 15 minutes & $59.89 \pm 5.27$ & $59.84 \pm 4.06$ & $0.964^{\mathrm{ns}}$ \\
\hline At 20 minutes & $60.44 \pm 5.46$ & $59.16 \pm 3.53$ & $0.187^{\mathrm{ns}}$ \\
\hline At 25 minutes & $60.64 \pm 5.87$ & $59.36 \pm 4.55$ & $0.247^{\mathrm{ns}}$ \\
\hline At 30 minutes & $61.91 \pm 5.48$ & $59.96 \pm 4.03$ & $0.057^{\mathrm{ns}}$ \\
\hline At 35 minutes & $60.42 \pm 5.44$ & $59.80 \pm 3.56$ & $0.523^{\mathrm{ns}}$ \\
\hline At 40 minutes & $61.71 \pm 5.45$ & $60.69 \pm 3.95$ & $0.311^{\mathrm{ns}}$ \\
\hline At 45 minutes & $64.05 \pm 6.89$ & $60.95 \pm 3.79$ & $0.014^{*}$ \\
\hline At 50 minutes & $62.64 \pm 6.79$ & $61.00 \pm 3.61$ & $0.524^{\mathrm{ns}}$ \\
\hline
\end{tabular}

Values are expressed as mean \pm SD. P value $<0.05$ is considered as significant Unpaired t test was done to measure the level of significance

*- significant, *** - very highly significant, ns- non significant 


\section{Discussion}

In the current study, 3(6.7\%) parturients in group $\mathrm{P}$ and none of the parturients in group $\mathrm{E}$ developed bradycardia which was treated by 0.5 $\mathrm{mg}$ atropine. The difference was statistically not significant $(\mathrm{p}=0.241)$. One study observed that 1 out of 30 women developed bradycardia who received phenylephrine and none in the women receiving ephedrine which was statistically not significant. The occurrence of bradycardia was less in their study because they used phenylephrine $80 \mu \mathrm{g}$ as a prophylactic dose. ${ }^{4}$ The results of our study are consistent with one study where none of the parturient receiving ephedrine developed bradycardia whereas $5(12.5 \%)$ parturient receiving phenylephrine developed bradycardia. ${ }^{5}$ Another study also found that maternal bradycardia was more frequent with phenylephrine than with ephedrine which was expected to be due to increase in blood pressure with an $\alpha$ agonist leading to reactive bradycardia (baroreceptor reflex) which was responsive to atropine without any adverse consequences. ${ }^{6}$

In the current study, 2(4.4\%) parturient in group $\mathrm{P}$ and $8(17.8 \%)$ parturient in group $\mathrm{E}$ developed tachycardia which was found to be statistically significant $(p=0.044)$. The result of this study is coherent with one report in which they reported significantly $(p<0.05)$ higher number of parturient receiving ephedrine developed tachycardia. ${ }^{7}$ However,another study conducted a similar study where neither bradycardia, nor tachycardia was noted because their definition of bradycardia was heart rate $<50 \mathrm{bpm}$ and of tachycardia was heart rate $>130 \mathrm{bpm}$. The incidence of tachycardia in group $\mathrm{E}$ can be explained by its mechanism of action as it has mixed action directly as well as indirectly on $\alpha$ and $\beta$ receptors whereas phenylephrine has pure $\alpha$ agonist property. ${ }^{8}$

In our study, we observed that the baseline systolic blood pressure, diastolic blood pressure were not significantly comparable between two groups. But the mean systolic blood pressure, diastolic blood pressure was significantly higher than in group E till the delivery of the baby.
However, the mean systolic blood pressure after delivery of the baby was higher in group $\mathrm{P}$ than in group $\mathrm{E}$ which was statistically significant but the mean diastolic blood pressure after the delivery of the baby was high in group $\mathrm{P}$ than in group $\mathrm{E}$ but was not statistically significant. The result of our study is consistent with one study which confirmed that single intravenous dose of phenylephrine $100 \mu \mathrm{g}$ was effective for treating hypotension after spinal anaesthesia for caesarean section. ${ }^{9}$

Furthermore, the result of our study is not consistent with one study because they preloaded the patients with $10 \mathrm{ml} / \mathrm{kg}$ normal saline. ${ }^{7}$ One article found that ephedrine was found to be more effective than phenylephrine in the prevention of maternal hypotension. This may have been because a lower dose of phenylephrine was used in their study compared to this study. ${ }^{10}$ In our study, maintenance of systolic blood pressure can also be explained by administration of crystalloid at the time of induction of subarachnoid block called co-loading at the rate of $20 \mathrm{ml} / \mathrm{kg}$.

In the current study statistical differences were observed in systolic and diastolic blood pressure in group $\mathrm{P}$ and group $\mathrm{E}$ till the delivery of the baby but the diastolic blood pressure was better maintained with phenylephrine than with ephedrine, this finding is consistent with one study. $^{11}$

\section{References}

1. Ayorinde, B., Buczkowski, P., Brown, J., Shah, J. and Buggy, D. (2001). 'Evaluation of pre-emptive intramuscular phenylephrine and ephedrine for reduction of spinal anaesthesia-induced hypotension during Caesarean section'. British Journal of Anaesthesia, 86(3), pp.372-76.

2. Aziz, N., Bangash, R., Khan, P. (2013). 'Comparison between ephedrine and phenylephrine in the prevention of post spinal hypotension during elective cesarean section'. J Med Sci, 21(1), pp.2730. 
3. Bhagat, H., Malhotra, K., Ghiilayal, SK., Srivastava, PC. (2004). 'Evaluation of preloading and vasoconstrictors as a combined prophylaxis for hypotension during subarachnoid anesthesia'. Indian $J$ Anaesth, 48, pp.299-303.

4. Brooker, R., Butterworth, J., Kitzman, D., Berman, J., Kashtan, H. and McKinley, A. (1997). Treatment of Hypotension after Hyperbaric Tetracaine Spinal Anesthesia. Anesthesiology, 86(4), pp.797-805.

5. Cooper, D., Carpenter, M., Mowbray, P., Desira, W., Ryall, D. and Kokri, M. (2002) 'Fetal and Maternal Effects of Phenylephrine and Ephedrine during Spinal Anesthesia for Cesarean Delivery'. Anesthesiology, 97(6), pp.158290.

6. Cooper, D., Sharma, S., Orakkan, P. and Gurung, S. (2010). Retrospective study of association between choice of vasopressor given during spinal anaesthesia for highrisk caesarean delivery and fetal pH. International Journal of Obstetric Anesthesia, 19(1), pp.44-49.

7. Cyna, A., Andrew, M., Emmett, R., Middleton, P. and Simmons, S. (2006). Techniques for preventing hypotension during spinal anaesthesia for caesarean section. Cochrane Database of Systematic Reviews.

8. Das, S., Mandal, M., Basu, S., Mukhopadhyay, S. and Mandal, S. (2011). A comparative study of infusions of phenylephrine, ephedrine and phenylephrine plus ephedrine on maternal haemodynamics in elective caesarean section. Indian Journal of Anaesthesia, 55(6), pp.578-83
9. Datta, S., Alper, M., Ohtheimer, G. And Weiss, J. (1982) 'Method of Ephedrine Administration and Nausea and Hypotension during Spinal Anesthesia for Cesarean Section'. Anesthesiology, 56(1), pp.68-69.

10. Datta, S. (1995). The Obstetric anesthesia handbook, $2^{\text {nd }}$ edition, Mosby Year Book, pp.29.

11. Dyer, RA., Farina, Z., Joubert, IA., Du, Toit P., Meyer, M., Torr, G. et al. (2004). 'Crystalloid preload versus rapid crystalloid administration after induction of spinal anaesthesia (coload) for elective caesarean section'. Anaesth Intensive Care, 32(3) pp.351-7. 